\title{
Decisions in software development projects management. An exploratory study
}

\author{
Ricardo Colomo-Palacios * \\ Universidad Carlos III de Madrid \\ Email: ricardo.colomo@uc3m.es \\ Cristina Casado-Lumbreras \\ Universidad Complutense de Madrid \\ Email: cristinacasadolumbreras@pdi.ucm.es \\ Pedro Soto-Acosta \\ Universidad de Murcia \\ psoto@um.es \\ Ángel García-Crespo \\ Universidad Carlos III de Madrid \\ Email: angel.garcia@uc3m.es \\ * Corresponding Author
}

\begin{abstract}
Given the importance of software in today's world, the development of software systems is a key activity that requires complex management scenarios. This paper explores the implications of hard decisions in the context of software development projects (SDPs). More in deep, it focuses on the emotional consequences of making hard decisions in IT organizations. Complex SDPs involve a great variety of actors. This fact entails morale, feelings and emotions, which play an important role for communication, interaction and, ultimately, decision making. The aim of the paper is twofold. First (study 1), to identify which are the most important hard decisions in SDPS. Second (study 2), to study the influence of emotions on decision-making processes (Study 2). Findings show the complex emotional consequences and difficulties that managers must face in hard decision-making processes.
\end{abstract}

\section{Keywords}

Hard decisions; Emotions; Software Project Management; Delphi Method; Decision Making 


\section{Introduction}

Software development is a human centric and socio-technical activity (Casado-Lumbreras et al., 2011) and a knowledge-intensive process (Chou, 2011). The task of managing a software project can be extremely complex, drawing on many personal, team and organizational resources (Rose et al., 2007; Soto-Acosta et al., 2010). The software development process is founded on three basic pillars: processes, technologies and people. These pillars are interconnected, forming an inseparable triangle on which organizations operate (Hernández-Lopez et al., 2010). The managing of this triangle is full of decisions and other managerial issues. Given this importance, numerous efforts to support and analyze decision making in these projects have been made. One important aspect is the diverse decision-making methods of professionals and management teams driving the projects. Thus, organizations end up with their own (ad hoc or formal) decision model for managing SDPs (Nguyen, 2006). Existing literature has proposed several tools to assist decision making in SDPs, which include: indicators (e.g. Basili 1996; Hopple, 1986), software project control centers (Münch \& Heidrich, 2004), system dynamics (e.g. Abdel-Hamid \& Madnick, 1991; Lee et al., 2009), checklists (Keil et al., 2008), decision models (e.g. Nguyen, 2006; Sakthivel, 1994) or multi-criteria decision analysis (e.g. Lai et al., 2002; Wang \& Lin, 2003).

The perspective of using the concept of hard decision in SDPS brings new research opportunities to software project development managers. According to Clemen (1996) and Clemen and Reilly (2001), hard decisions are characterized by four aspects:

1. the complexity of the problem;

2. uncertainty inherent in the situation;

3. the decision-maker being interested in working towards multiple objectives but progress in one direction impeding progress in others;

4. different perspectives leading to different conclusions.

The importance and applicability of the concept of hard decisions in SDPs can be considered as capital in such environments. Given the key role human resources in SDPs (Colomo-Palacios et al., 2010; Colomo-Palacios et al., 2011), knowing which circumstances and decisions change the evolution of SDPs project is key for practitioners and researchers alike.

Furthermore, the study of emotions within software development teams also represents an prominent research area. Thanasankit (2002) argued that organizations need to go further and consider the emotions and culture of users and software specialists. As a result of this interest, Gallivan (2003) studied emotion, among other factors in software process innovation. McGrath (2006) delved deeper into the role of emotions in information systems and organizational change. Evaristo (2003) pointed out the importance of controlling member emotions in multicultural projects. Other authors have cited emotions as a crucial factor in requirements engineering (e.g. Macaulay, 1999; Ramos et al., 2005). McBride (2008) studied the importance of human aspects including, among others, emotions in software quality. Napier et al. (2009) considered the use of emotions by successful project managers. Recently, Casado-Lumbreras et al. (2010) examined the importance of emotions for IT workers in general. However, there are no studies in the literature that link emotions and decisions along with finding the implications of emotions in the context of managerial decisions within SPDs.

Taking into account the importance of decisions in SDPs and the role played by emotions in such contexts, the aim of the paper is two-fold. First, to identify which are the most important hard decisions in SDPs (study 1). Second, to discuss the influence of emotions on decision 
making processes (study 2). The research design (two studies) responds to the need to obtain two different results from the exploratory study that constitutes the paper. The first study aims to identify hard decisions in SDPs, and this identification must be performed without the contamination that could come from the discovery and analysis of emotions. The second study is performed once the results of the first study are obtained.

The remainder of the paper is structured as follows. The next section describes the first study, which aims to identify hard decisions in SDPs. This section includes a description of the method, sample and results. Following that, the second study is presented including a description of the method, sample, the results and the data analysis. Finally, the paper ends with a discussion of research findings, limitations and concluding remarks.

\section{STUDY 1: identifying hard decisions in SDPs}

\section{METHOD}

The Delphi method was used for gathering and analyzing data for this study. The objective of this study was to identify an initial set of hard decisions in SDPS. The aim is to obtain the most reliable consensus of opinion of a group of experts, which is why Delphi was selected. Given that the essence of the Delphi consensus method is to derive quantitative estimates through the qualitative assessment of evidence, this method permits researchers to reach their objectives.

The Delphi Method, developed by Dalkey and Helmer (1963), has been widely used to obtain a consistent flow of answers through using questionnaires. This method originated in a series of studies that the RAND Corporation conducted in the 1950s (Okoli \& Pawlowski, 2004). It is an expert opinion survey method with three features (Landeta 2006): anonymous response, iteration and controlled feedback and, lastly, statistical group response. Although this method was developed many years ago, it continues to be used and is a valid instrument for forecasting and supporting decision making (Landeta, 2006). Finally, the Delphi method has proven itself to be a popular and effective tool in information systems research (e.g. Hayne \& Pollard, 2000; Schmidt et al., 2001; Holsapple \& Joshi, 2002; Keil, Tiwana \& Bush, 2002; Lai \& Chung, 2002; Mulligan, 2002; Moløkken-Østvold \& Jørgensen, 2004).

For Study 1 a panel of experts was selected. Each expert was asked to record hard decisions in a software development scenario (Phase 1). Next, individual responses were collected and aggregated, leaving just five Hard Decisions. These items were later ranked by experts (Phase 2). Rankings were collated and the overall ranking computed.

In Phase 1, the panelists were asked to select 5 hard decisions related to SDPs. In Phase 2, panelists were presented with an ordered list of hard decisions from Phase 1 . The ordering of the hard decisions was based upon the percentage of panelists who selected each decision in Phase 1 . Thus, based on feedback from the group's initial selection process, the panelists were then asked to rank each item. At the end of Phase 2, a mean rank for each factor was computed and Kendall's coefficient of concordance (W) was calculated to determine the degree of consensus among the panelists (Schmidt, 1997). This statistic assesses the overall degree of agreement in a set of rankings given by several individuals (Siegel, 1956: 229-239).

\section{SAMPLE}


The sample was composed of 25 panelists, each of whom was selected on the basis of his/her previous experience in SDPs. Nine were women (36\%) and 16 men (64\%). The average age of the sample was 37.1. On average, the users on the panel had 17 years experience.

\section{RESULTS}

Table 1 shows the results of 96 Hard Decisions provided by experts (some experts did not provide 5 items) grouped in coherent items:

Table 1. Study 1 Phase 1 results: hard decisions.

\begin{tabular}{|l|r|r|}
\hline Decision & $\#$ & $\mathbf{\%}$ \\
\hline Project prioritization & 15 & $16 \%$ \\
\hline Requirements prioritization & 13 & $14 \%$ \\
\hline Development strategy election & 10 & $10 \%$ \\
\hline Partner-Supplier election & 9 & $9 \%$ \\
\hline Selecting internal personnel & 9 & $9 \%$ \\
\hline Risk prioritization & 7 & $7 \%$ \\
\hline Recruiting external personnel & 7 & $7 \%$ \\
\hline Firing a team member & 5 & $5 \%$ \\
\hline Acceptance of change in requirements & 4 & $4 \%$ \\
\hline Developing a new application instead of maintaining it & 3 & $3 \%$ \\
\hline Others & 14 & $15 \%$ \\
\hline TOTAL & 96 & $100 \%$ \\
\hline
\end{tabular}

Taking into account results presented in Table 1, the hard decisions will be: Project prioritization, Requirements prioritization, Development strategy election, Partner-Supplier election and Internal personnel selection. The five hard decisions selected by a simple majority of the participants were retained for the next phase. The aim of this study is to propose a ranking of decision emotions in order to analyze the emotions presented in these decisions. Given the nature of our study (exploratory), having limited factors will facilitate the later recollection, analysis and discussion process.

In Phase 2, panelists were presented with an ordered list of decisions from Phase 1. The ordering of the decisions was based upon the percentage of panelists who selected each hard decision in Phase 1. Kendall's coefficient of concordance (W) was computed to assess whether there was significant agreement on the rank order among participants. The responses of the panelist were concordant (Kendall's coefficient of concordance, $\mathrm{W}=0.625, \mathrm{n}=25, \mathrm{P}<0.01$ ). Rank results are displayed in Table 2:

Table 2. Study 1 Phase 2 Results: Hard Decisions Ranking.

\begin{tabular}{|l|r|r|r|r|r|r|}
\hline Decision & Rank & Rank 1\# & Rank 2\# & Rank 3\# & Rank 4\# & Rank 5\# \\
\hline Project prioritization & 1 & 14 & 10 & 1 & 0 & 0 \\
\hline Requirements prioritization & 2 & 8 & 13 & 3 & 1 & 0 \\
\hline Selecting internal personnel & 3 & 2 & 0 & 11 & 6 & 6 \\
\hline Partner-Supplier election & 4 & 1 & 1 & 6 & 13 & 4 \\
\hline
\end{tabular}




\begin{tabular}{|l|l|l|l|l|l|l|}
\hline Development strategy election & 5 & 0 & 1 & 4 & 5 & 15 \\
\hline
\end{tabular}

\section{STUDY 2: the influence of emotions on hard decisions in SDPs}

\section{METHOD}

Thirty managers with broad experience in software development project management were interviewed. Through a semi-structured questionnaire, they were interrogated about the presence of emotions in decision-making processes. Some of the questions are listed as follows:

- From the 5 hard decisions selected, which ones are more affected by feelings and emotions?

- Which are the main emotions associated with the different decision-making processes?

A semi-structured interview was employed since this qualitative method brings rich information about a highly subjective issue. It is not in vain that "qualitative methods can give the intricate details of phenomena that are difficult to convey with quantitative methods" (Strauss \& Corbin, 1990, p. 19). However, according to Jick (1983, p. 135) qualitative and quantitative methods should be "viewed as complementary rather than as rival camps". Although the method employed for data collection is qualitative, a factor analysis (a quantitative method) was performed in order to obtain richer results.

There are six basic emotions, known as primary emotions or universal emotions: Anger, Happiness, Fear, Sadness, Disgust and Surprise (Ekman, 1984; Ekman, 1992; Ortony \& Turner, 1990). To provide a list of emotions to participants, the four basic emotions (anger, joy, fear and sadness) and their subordinates were considered. We removed "disgust" and "surprise" from the list because their translation did not denote conditional everyday emotions.

Table 3 contains the list of emotions ordered in terms of their relationship with the four basic emotions selected. In any case, the presentation of the list of emotions to the participants consisted of a random presentation of these words.

Table 3. List of emotions offered to participants

\begin{tabular}{|c|c|c|c|}
\hline Anger & Happiness & Fear & Sadness \\
\hline Anger & Happiness & Fear & Sadness \\
\hline Frustration & Joyfulness & $\begin{array}{c}\text { Being } \\
\text { afraid }\end{array}$ & Depression \\
\hline Rage & Gladness & $\begin{array}{c}\text { Being } \\
\text { scared }\end{array}$ & Sorrow \\
\hline & Content & Insecurity & Grief \\
\hline Annoyance & Satisfaction & Anxiety & Helplessness \\
\hline Irritation & & Panic & Resignation \\
\hline
\end{tabular}

The qualitative analysis for the present study was carried out with the help of the qualitative data analysis software NVIVO 2.0 (International QSR Pty Ltd).

\section{SAMPLE}


The sample consisted of 30 managers from different multinational European and American organizations. The average age was 46.3 years and their average experience in high responsibility positions in software development was 19 years. Eleven subjects were women (37\%) and nineteen men (63\%).

\section{RESULTS}

Table 4 shows the emotions selected by experts. According to respondents, these emotions reflected the subjects' feelings during decision-making processes. Unlike, they suggested that other emotions, presented in Table 3, did not describe feelings in decision-making processes.

Table 4. Emotions identified by participants

\begin{tabular}{|c|c|c|c|}
\hline Anger & Happyness & Fear & Sadness \\
\hline Anger & & & \\
\hline Frustration & & & \\
\hline & & & \\
\hline & & & \\
\hline Annoyance & $\begin{array}{r}\text { Pleasure/Satisfac } \\
\text { tion }\end{array}$ & Anxiety & Helplessness \\
\hline & & & Resignation \\
\hline
\end{tabular}

Table 5 summarizes the list of emotions and their frequency associated with the different decision-making processes identified by the participants.

Table 5. Emotions related to decision making processes

\begin{tabular}{|l|r|r|r|r|r|r|}
\cline { 2 - 7 } \multicolumn{1}{c|}{} & $\begin{array}{r}\text { Project } \\
\text { prioritizati } \\
\text { on }\end{array}$ & $\begin{array}{r}\text { Requirements } \\
\text { prioritization }\end{array}$ & $\begin{array}{r}\text { Selecting } \\
\text { internal } \\
\text { personnel }\end{array}$ & $\begin{array}{r}\text { Partner- } \\
\text { Supplier } \\
\text { election }\end{array}$ & $\begin{array}{r}\text { Development } \\
\text { strategy } \\
\text { election }\end{array}$ & TOTAL \\
\hline Anxiety & 13 & 13 & 18 & 14 & 20 & $\mathbf{7 8}$ \\
\hline Frustration & 18 & 18 & 14 & 17 & 13 & $\mathbf{8 0}$ \\
\hline Anger & 12 & 10 & 6 & 14 & 9 & $\mathbf{5 1}$ \\
\hline Helplessness & 2 & 4 & 7 & 4 & 5 & $\mathbf{2 2}$ \\
\hline Resignation & 21 & 19 & 22 & 15 & 20 & $\mathbf{9 7}$ \\
\hline Annoyance & 14 & 23 & 6 & 9 & 12 & $\mathbf{6 4}$ \\
\hline Pleasure/ & 1 & 1 & 6 & 4 & 6 & $\mathbf{1 8}$ \\
Satisfaction & & & & & & $\mathbf{8 1 0}$ \\
\hline TOTAL & $\mathbf{8 1}$ & $\mathbf{8 8}$ & $\mathbf{7 9}$ & $\mathbf{7 7}$ & $\mathbf{8 5}$ & $\mathbf{4 1 0}$ \\
\hline
\end{tabular}

As we can see, in general, negative emotions were presented to a greater or lesser extent in the five decision-making processes identified. In particular, Resignation and Frustration were emotions mentioned by a larger number of participants in relation to different decision-making processes.

Participants mentioned that Resignation is especially significant in Selecting internal personnel (73\% of respondents), Project Prioritization (70\%), Development strategy election (66\%) and Requirements prioritization (63\%). One of the subjects stated that Resignation "represents acceptance or conformity in situations that cannot be changed or it is complicated to 
do so". According to participants, Resignation "represents consent to something that we disagree with or reject, but we seem incapable of changing".

Frustration had also a major presence in Project Prioritization (60\%), Requirements Prioritization (60\%) and Partner-Supplier election (57\%). Frustration illustrates a specific component of anger, that is, the fact of not being able to achieve foreseen objectives or goals, or the insistence of stakeholders to defend their interests only that may turn project management into a frustrating process. Therefore, the significant presence of these two emotional states (Frustration and Anger) in most decision-making processes revealed that, in the situations in which managers are involved, they should agree with adverse situations, often in addition to accepting failure to achieve one's goals or needs.

Anxiety was especially evident in the choice of development strategy (66\%) and in selection of personnel (60\%). According to respondents, Anxiety is mainly due to difficulties in communication between different spokespeople. As a result, it prevents achieving understanding, agreement or consensus. Managers also mentioned Anxiety as a consequence of delays in decision-making processes and slowness in the progress of communications and negotiations.

Annoyance was mainly mentioned in the prioritization of requirements (77\%), reportedly due to "communication difficulties with partners with apparently opposing interests or needs". These factors also are involved in the state of Frustration and Anger.

In turn, Anger, in its broadest sense, was considered to be less frequent than frustration, but it had an important presence. Anger was suggested to be present in Partner-Supplier election (47\%) and Project prioritization (40\%). Anger factors are the same ones as those that create frustration, that is, the incapacity between negotiators to understand common interests and objectives, their incapacity to empathize with the rest, their lack of overall perspective, and consequently their incompetence in negotiating and sealing deals.

Helplessness showed a scant but disturbing presence. Despite the decision-making authority and influence of these professionals, they may sometimes respond with helplessness. This emotional state represents an even more dramatic consequence; the manager has reached a point where he thinks that no matter what he or she does, it will be useless. As informers state: "Helplessness is a more negative evolution of Resignation because it means the absence of action”.

Finally, the only positive emotional state mentioned by the managers, Pleasure / Satisfaction, showed a more limited presence in each of the processes of decision making. The highest percentage - 20\% of the sample - is presented in Development strategy election and Selecting internal personnel.

\section{DATA ANALYSIS}

As mentioned, Resignation and Frustration received a higher percentage of reference for the various decision-making processes. However, they represent different emotional states that we believe will result in significant differences between them. This was confirmed by the t-test for related samples, which showed significant differences between Resignation and Frustration $(\mathrm{t}(149)=-2.039, \mathrm{p}<0.05)$.

Also, significant differences between Resignation and Anger (t $(149)=-5.705, \mathrm{p}<0.05)$ and between Resignation and Annoyance $(\mathrm{t}(149)=3.108, \mathrm{p}<0.05)$ were found.

However, no significant difference between Resignation and Anxiety (t (149) =- 1.312, p> 0.05) were encountered, indicating that their presence in terms of different decision-making processes shows a similar pattern.

With respect to the presence of emotions in terms of individual decision-making processes, an ANOVA analysis indicated that there were no significant differences in Anxiety in the various decision-making processes $(\mathrm{F}(4)=0.899, \mathrm{p}>0.05)$. Moreover, No significant differences were found for Frustration $(\mathrm{F}(4)=0.365$, p $>0.05)$; Anger $(\mathrm{F}(4)=1.189, \mathrm{p}<0.05$; 
Helplessness $(\mathrm{F}(4)=0.870, \mathrm{p}>0.05)$ and Resignation $(\mathrm{F}(4)=0.639, \mathrm{p}<0.05)$. These findings indicate that these emotions appear in a similar way, regardless of the decision-making process.

Finally, we tried to confirm that the broad spectrum provided by the subject's emotional state seems to be grounded in three main emotions: Resignation, Frustration and Anxiety. To test how these factors can explain most of the variance, we applied a factor analysis, using the method of principal components with the use of varimax orthogonal rotation. Three factors were extracted, eliminating saturations below 0.30. A principal objective of the factor analysis is to attain a parsimonious description of observed data (Harman, 1976). This method allows reducing the complexity of data and reaching a conclusion, which is the aim of our explorative study. More in depth, the aim of this method in our study was to confirm the importance of certain emotions compared to others and their independence of each other.

The first factor, which explained $22.58 \%$ of the variance, showed high saturations in Resignation and Helplessness. The second factor, which explained $41.57 \%$ of the variance, presents high saturation in Anxiety and moderate in Annoyance. Finally, the third factor, which explains 57.59\% of the variance, presented high saturation in Frustration and Anger.

Table 6. Factorial Analysis for emotions related to decision-making processes

\begin{tabular}{|l|c|c|c|}
\cline { 2 - 4 } \multicolumn{1}{c|}{} & \multicolumn{3}{c|}{ Factors } \\
\cline { 2 - 4 } \multicolumn{1}{c|}{} & $\mathbf{1}$ & $\mathbf{2}$ & $\mathbf{3}$ \\
\hline Anxiety & & 0.861 & 0.915 \\
\hline Frustration & & & 0.519 \\
\hline Anger & & & \\
\hline Helplessness & 0.551 & & \\
\hline Resignation & 0.735 & 0.563 & \\
\hline Annoyance & & & \\
\hline Pleased & & & \\
\hline
\end{tabular}

Thus, factor analysis confirmed that Resignation, Frustration and Anxiety were the most influential emotions, and, moreover, were relatively independent. The implications of these findings are twofold. First, emotions are relatively independent and there are no large overlaps among them. Second, this circumstance means that emotions can be identified, diagnosed and intervened in an isolate way.

\section{DISCUSSION}

First of all, the findings show that project and requirements prioritization, selecting internal personnel, partner-supplier election and development strategy election all represent the main processes in hard decision-making for managers in charge of software development project management. Thus, there are many processes in which managers have to face emotionally complex decisions.

A critical aspect of IT management is the decision whereby the best set of projects is selected from many competing proposals (Badri, Davis, \& Davis, 2001). However, IT project selection is difficult because there are lots of quantitative and qualitative factors to be considered in the candidate IT projects such as business goals, benefits, project risks and available resources (Asosheh, Nalchigar \& Jamporazmey, 2010). Project prioritization was the top ranked hard decision in our study. The reasons for this may be rooted in the direct influence on strategic direction of the company (Holtsnider \& Jaffe, 2007). These decisions could imply an enhancement of the operational competitive advantage of a business (Chen \& Cheng, 2008). 
Requirements prioritization was recognized as an important, but, at the same time, challenging activity that needed complex decision making. This finding is in line with recent research (e.g. Berander \& Svahnberg, 2009; Perini, Rica \& Susi, 2009). Yet there has been little research into decision-making process around requirement selection (Barney, Aurum \& Wohlin, 2008). There are many prioritization techniques available for project managers, but, according to Petersen and Wohlin (2009), requirements prioritization is critical and at the same time hard to create and maintain. The results of our study confirm that negative emotions are involved in requirements prioritization (frustration, resignation and annoyance), even when there are prioritization tools available.

As regards personnel selection, personnel assignment decisions have been highlighted by several authors in the literature (e.g. Acuña, Juristo \& Moreno, 2006; Naveh et al., 2007). Properly assigning people to development roles is crucial for creating productive software development teams (Acuña \& Juristo, 2004). On the other hand, wrong assignments may result in significant loss of value due to understaffing, under qualification or over qualification of assigned personnel, and high turnover of poorly matched workers (Naveh et al., 2007). Due to the lack of proper methods to assess personnel capabilities, decision makers are forced to assign resources to tasks based on subjective measures only (Otero et al., 2009), not in vain are the works where the assignment of personnel to software project teams is modeled scarce (Andre-Ampuero, Baldoquín de la Peña \& Acuña, 2010) although the assignment problem has been an object of study for several decades. Furthermore, it is evident that there is much room for improved personnel assignment methodologies in software projects (Otero et al., 2009). This lack of maturity was also reflected in our study: Selecting internal personnel is the third most valued hard decision according to respondents.

Finally, the issues about the difficulty of outsourcing also appear in the study and, as a result of this, Partner-Supplier election was the fourth hard decision listed. This appearance confirms the caveats of software outsourcing detected in the literature in a profuse way (e.g. Beasley, Bradford \& Dehning, 2009; Chou \& Chou, 2009; Lacity, Khan, \& Willcocks, 2009; Nakatsu \& Iacovou, 2009).

The work of García-Crespo et al. (2010) provided a set of decisions that constitute high risk factors in a Global Software Development (GSD) scenario. The comparison of these factors with those from the study presented in this paper could also shed light into the differences between traditional SDPs and GSDs. Table 7 shows the relative importance of these factors in both scenarios, Partner selection is much higher in GSD, while there are factors not present in GSD that are crucial for SDPs, such as Project prioritization and Requirements prioritization. Finally some factors like Selecting internal personnel and Development strategy election are present in both studies with similar values.

Table 7. Decision-making processes in SDPs and GSD environments

\begin{tabular}{|l|r|r|}
\hline Decision & SDPs Rank & GSD Rank \\
\hline Project prioritization & 1 & - \\
\hline Requirements prioritization & 2 & - \\
\hline Development strategy election & 3 & 5 \\
\hline Partner-Supplier election & 3 & 1 \\
\hline Selecting internal personnel & 5 & 6 \\
\hline Work packages assignation & - & 2 \\
\hline
\end{tabular}




\begin{tabular}{|l|r|r|}
\hline Choose coordination mechanisms \& tools & - & 3 \\
\hline Firing supplier & - & 4 \\
\hline
\end{tabular}

Study 1 confirmed the importance of several issues related to SDPs management and, apart from this, bases its novelty on the ranking provided of hard decisions that, in a sense, can be used to prevent higher risks in SDPs. Practitioners should carefully examine and adopt tools provided in the literature to accomplish managerial tasks and support decision making processes in order to minimize the inherent risk of SDPs. Having such tools and models will make decision making a process based on best practices, and not only on intuition.

As regards Study 2, the outcome showed that the global conception of managers regarding emotions and their implication in decision-making processes endorse the traditional western conception of the dichotomy between the rational side, represented by decision making, and the emotional side. The western philosophical tradition whose origin can be traced to Ancient Greece, has always envisaged emotions as unpredictable experiences, incompatible with sensitive and intelligent judgments. Fundamentally, we regard emotions or feelings-based decisionmaking processes with contempt. When people react emotionally, we perceive that they are regressing and showing their primitive animal nature. This philosophical standpoint which originated thousand years ago remains in the Western zeitgeist and as a consequence has a remarkable impact on the everyday conception that people show regarding psychological processes. Therefore, emotion and cognition have been in conflict since the very first intellectual western productions.

Is this negative conception of emotions what determined the choice of five negative emotions -Resignation, Frustration, Anxiety, Annoyance and Anger- as those mainly related to decisionmaking processes in development projects? It seems reasonable to think that emotions associated with decision making are preferably negative due to the requirement and complexity of software project management. In fact, the only positive emotion identified -pleasure-, is barely mentioned in all decision-making processes and, hence, a notable stress level experimented by managers may be induced. Moreover, in the first part of Study 2, managers interviewed about the influence of emotions, mentioned positive emotions such as pride, which also affected their attitudes and decisions in a negative manner.

Likewise, emotions such as Resignation and Frustration may be considered uncharacteristic of professionals with decision capacity and influence as well as of those with extensive experience as managers. Is it possible that these responses are generated after an emotional demonstration - Resignation, Frustration - that has psychological weariness as its only outcome? Is the emotional demand in management so high that the natural evolution is towards Resignation, Frustration and Anxiety? These kinds of emotions in which managers give up and expect neither to achieve their goals nor change a reality that they repudiate are likely to illustrate once again the emotional demand of technology project management.

These emotions have been present in the IT literature (Acuña, Gómez \& Juristo, 2009; Huang, 2009; Lin \& Huang, 2009; Lin \& Huang, 2010; Shim et al., 2010), however, the link of these emotions with the decision making processes present in SDPs is new. This link is the second big contribution of this work to the literature. From a practical standpoint, SDPs managers should be trained to face these emotions in order to control their implications in their performance and to produce decisions without these having a big influence on their behavior. 


\section{Conclusions and future work}

According to the results of this paper, managing SDPs is a demanding activity. On the one hand, there are many hard decision-making processes involved, and on the other, the emotions present in these processes are mainly negative.

One of the initial hypotheses of this study established that negative emotions will show a major presence in more demanding decision-making processes. However, results show that negative emotions are present in all hard decision making, even if the sample is composed of highly-skilled professionals where emotions like Anxiety or Resignation are not common beforehand. Anxiety may be more suitable for less experienced professionals or those with a greater degree of insecurity. On the other hand, resignation, can be linked to people with little influence and discretion.

We believe that it is necessary to investigate in future research the antecedents and consequences of the analyzed emotions and their degree of intensity. While we have ascertained whether an emotion was present in a given process, and the number of participants who mentioned it, we did not assess whether an emotional state is more intense than another, and consequently, potentially more harmful to performance and management.

Another reflection related to this emotional evolution of "depressive nature" may be added: is it possible that this could be explained by a lack of skills or competences of managers?

In work environments, a higher importance of technical competences over interpersonal skills in training was noticed. This tendency is present in organizations, even in those where the training investment includes skills training. The demanding situation of SDPs and the characteristic stress suffered by the technology sector should result in specific forms of psychological training to satisfy the demands of these professionals. The work of Tichon and Wallis (2010) could shed some light into stress training. We are currently developing a specific program of emotional training intended for managers and board members of large technological enterprises, with the aid of several H.R. departments. This program is not only designed to train the interpersonal skills required for suitable technological project management, but is also focused on modifying traditional manager conceptions such as the consideration that emotions are negative, disturbing and, ultimately, a factor in decision-making failure. This training contemplates the possibility of teaching empowerment or optimism and, in effect, training head managers to manage every emotion, positive and negative, in order to facilitate project and personnel management. Practitioners should be aware of the importance of emotions in working environments and develop and adapt their emotional responses to difficult situations. People are crucial for software development. Taking into account that emotions are linked in an intimate way to humans, the emotions of SDPs managers must be trained in order to reduce project risks. Thus, SDPs managers are expected to require considerable skills not only for dealing with employees' feelings but also to manage their own. Managing emotional competences is more than necessary and has been reflected in existing research. We believe that it will be a prominent field of research in the next years.

\section{References}

Abdel-Hamid, T.K., \& Madnick, S.E. (1991). Software Project Dynamics: An Integrated Approach. Englewood Cliffs, NJ: Prentice-Hall. 
Acuña, S.T., Gómez, M., \& Juristo, N. (2009). How do personality, team processes and task characteristics relate to job satisfaction and software quality?. Information and Software Technology, 51(3), 627-639.

Acuña, S.T., Juristo, N., \& Moreno, A.M. (2006). Emphasizing Human Capabilities in Software Development. IEEE Software, 23(2), 94-101.

Acuña, S.T., \& Juristo, N. (2004). Assigning people to roles in software projects. SoftwarePractice and Experience, 34(7), 675-696.

Andre-Ampuero, M., Baldoquín de la Peña, M.G., \& Acuña, S.T. (2010). Identification of Patterns for the Formation of Software Development Projects Teams. International Journal of Human Capital and Information Technology Professionals, 1(3), 70-81.

Asosheh, A., Nalchigar, S. \& Jamporazmey, M. (2010). Information technology project evaluation: An integrated data envelopment analysis and balanced scorecard approach. Expert Systems with Applications, 37 (8), 5931-5938.

Badri, M.A., Davis, D., \& Davis, D. (2001). A comprehensive 0-1 goal programming model for project selection, International Journal of Project Management, 19 (4), 243-252.

Barney, S., Aurum, A., \& Wohlin, C. (2008). A product management challenge: Creating software product value through requirements selection. Journal of Systems Architecture, 54 (6), 576-593.

Basili, V.R. (1996). Applying the Goal/Question/Metric Paradigm in the Experience Factory. Software Quality Assurance and Measurement: A Worldwide Perspective. Publishing: London, UK.: International Thomson.

Beasley, M., Bradford, M., \& Dehning, B. (2009). The value impact of strategic intent on firms engaged in information systems outsourcing. International Journal of Accounting Information Systems, 10(2), 79-96.

Berander, P. \& Svahnberg, M., (2009). Evaluating two ways of calculating priorities in requirements hierarchies - An experiment on hierarchical cumulative voting. Journal of Systems and Software, 82(5), 836-850.

Casado-Lumbreras, C., García-Crespo, A., Colomo-Palacios, R., \& Gómez-Berbís, J.M., (2010). Emotions and interpersonal skills for IT professionals: an exploratory study. International Journal of Technology Enhanced Learning, 2(3), 215-226.

Casado-Lumbreras, C., Colomo-Palacios, R., Soto-Acosta, P., \& Misra, S. (2011). Culture dimensions in software development industry: The effects of mentoring. Scientific Research and Essays, 6(11), 2403-2412.

Chen, C.T., \& Cheng, H.L. (2008). A comprehensive model for selecting information system project under fuzzy environment. International Journal of Project Management, 27 (4), 389-399.

Chou, D.C., \& Chou, A.Y. (2009). Information systems outsourcing life cycle and risks analysis. Computer Standards \& Interfaces, 31(5), 1036-1043.

Chou, S. (2011). Management of system development knowledge: a cognitive approach. Behaviour \& Information Technology, 30(3), 389-401.

Clemen, R.T. (1996). Making Hard Decisions: An Introduction to Decision Analysis, second edition. Belmont, CA: Duxbury Press.

Clemen, R.T., \& Reilly, T. (2001). Making hard decisions with decision tools. Belmont, CA: Duxbury Press.

Colomo Palacios, R., Tovar Caro, E., García Crespo, A., \& Gómez Berbís, J.M. (2010). Identifying Technical Competences of IT Professionals: The Case of Software Engineers. International Journal of Human Capital and Information Technology Professionals, 1(1), 31-43. 
Colomo-Palacios, R., Fernandes, E., Soto-Acosta, P., \& Sabbagh, M. (2011). Software product evolution for Intellectual Capital Management: The case of Meta4 PeopleNet. International Journal of Information Management, 31(4), 395-399.

Dalkey, N., \& Helmer, O. (1963). An experimental application of the delphi method to the use of experts. Management Science, 9(3), 458-467.

Ekman, P. (1984). Expression and the nature of emotion. En K. Scherer y P. Ekman (eds.), Approaches to emotion. Hillsdale, NJ: Erlbaum.

Ekman, P. (1992). An argument for basic emotions. Cognition and Emotion, 6 (3/4), 169-200.

Evaristo, R. (2003). The management of distributed projects across cultures. Journal of Global Information Management, 11(4), 58-70.

Gallivan, J. (2003). The influence of software developers' creative style on their attitudes to and assimilation of a software process innovation. Information \& Management, 40 (5), 443-465.

García-Crespo, Á., Colomo-Palacios, R., Soto-Acosta, P., \& Ruano-Mayoral, M. (2010). A Qualitative Study of Hard Decision Making in Managing Global Software Development Teams. Information Systems Management, 27(3), 247-252.

Harman, H.H. (1976). Modern factor analysis. Chicago: The University of Chicago Press.

Hayne, S.C. \& Pollard, C.E. (2000). A comparative analysis of critical issues facing Canadian information systems personnel: a national and global perspective. Information \& Management, 38(2), 73-86.

Hernández-López, A., Colomo-Palacios, R., García-Crespo, Á., \& Soto-Acosta, P. (2010). Team Software Process in GSD Teams: A study of new work practices and models. International Journal of Human Capital and Information Technology Professionals, 1(3), 32-53.

Holsapple, C.W. \& Joshi, K.D. (2002). Knowledge manipulation activities: results of a Delphi study. Information \& Management, 39 (6), 477-490.

Holtsnider, B. \& Jaffe, B. (2007). IT manager's handbook: Getting your new job done (2nd ed.), Morgan Kaufmann Publishers

Hopple, G.W. (1986). Decision aiding dangers: the law of the hammer and other maxims. IEEE Transactions on Systems, Man, and Cybernetics, 16 (6), 948-963.

Huang, C.C. (2009). Knowledge sharing and group cohesiveness on performance: An empirical study of technology R\&D teams in Taiwan. Technovation, 29 (11), 786-797.

Jick, T.D. (1983). Mixing qualitative and quantitative methods. In Van Maanen, J. (Ed.), Qualitative Methodology, London: Sage.

Keil, M., Li, L., Mathiassen, L., \& Zhenga, G. (2008). The influence of checklists and roles on software practitioner risk perception and decision-making. Journal of Systems and Software, 81 (6), 908-919.

Keil, M., Tiwana, A., \& Bush, A. (2002). Reconciling user and project manager perceptions of IT project risk: a Delphi study. Information Systems Journal, 12 (2), 103-119.

Lacity, M.C., Khan, S.A. \& Willcocks, L.P. (2009). A review of the IT outsourcing literature: Insights for practice. The Journal of Strategic Information Systems, 18(3), 130-146.

Lai, V.S. \& Chung, W. (2002). Managing international data communications. Information \& Management, 45 (3), 89-93.

Lai, V.S., Wong, B.K., \& Cheung, W. (2002). Group decision making in a multiple criteria environment: a case using the AHP in software selection. European Journal of Operational Research, 137 (1), 134-144.

Landeta, J. (2006). Current validity of the Delphi method in social sciences. Technological Forecasting \& Social Change, 73 (5), 467-482 
Lee, S., Celik, N., \& Son, Y.J. (2009). An integrated simulation modelling framework for decision aids in enterprise software development process. International Journal of Simulation and Process Modelling, 5 (1), 62-76.

Lin, T.C., \& Huang, C.C. (2010). Withholding effort in knowledge contribution: The role of social exchange and social cognitive on project teams. Information \& Management, 47(3), 188196.

Lin, T.C., \& Huang, C.C. (2009). Understanding social loafing in knowledge contribution from the perspectives of justice and trust. Expert Systems with Applications, 36(3) Part 2, 61566163.

Macaulay, L.A. (1999). Seven-layer model of the role of the facilitator in requirements engineering. Requirements Engineering, 4 (1), 38-59.

McBride, N. (2008). Using performance ethnography to explore the human aspects of software quality. Information Technology \& People, 21 (1), 91-111.

McGrath, K. (2006). Affection not affliction: The role of emotions in information systems and organizational change. Information and Organization, 16 (4), 277-303.

Moløkken-Østvold, K., \& Jørgensen, M. (2004). Group Processes in Software Effort Estimation. Empirical Software Engineering, 9 (4), 315-334.

Mulligan, P. (2002). Specification of a capability-based IT classification framework. Information \& Management, 39 (8), 647-658.

Münch, J., \& Heidrich, J. (2004). Software project control centers: concepts and approaches. Journal of Systems and Software, 70(1-2), 3-19.

Nakatsu, R.B. \& Iacovou, C.L. (2009). A comparative study of important risk factors involved in offshore and domestic outsourcing of software development projects: A two-panel Delphi study. Information \& Management, 46 (1), 57-68.

Napier, N.P., Keil, M., \& Tan, F.B. (2009). IT project managers' construction of successful project management practice: a repertory grid investigation. Information Systems Journal, 19 (3), 255-282.

Naveh, Y., Richter, Y., Altshuler, Y., Gresh, D.L., \& Connors, P. (2007). Workforce optimization: identification and assignment of professional workers using constraint programming. IBM Journal of Research and Development, 51(3), 263-279.

Nguyen, T.N. (2006). A decision model for managing software development projects. Information \& Management, 43 (1), 63-75.

Okoli, C., \& Pawlowski, S.D. (2004). The Delphi method as a research tool: an example, design considerations and applications. Information \& Management, 42 (1), 15-29

Ortony, A., \& Turner, T.J. (1990). What's basic about basic emotions. Psychological Review, 97 (3), 315-331.

Otero, L.D., Centeno, G., Ruiz-Torres, A.J., \& Otero, C.E. (2009). A systematic approach for resource allocation in software projects. Computers \& Industrial Engineering, 56 (4), 1333-1339.

Perini, A., Rica, F., \& Susi, A. (2009). Tool-supported requirements prioritization: Comparing the AHP and CBRank methods. Information and Software Technology, 51 (6), 1021-1032.

Petersen, K., \& Wohlin, C. (2009). A comparison of issues and advantages in agile and incremental development between state of the art and an industrial case. Journal of Systems and Software, 82 (9), 1479-1490.

Ramos, I., Berry, D.M., \& Carvalho, J.A. (2005). Requirements engineering for organizational transformation. Information \& Software Technology, 47 (7), 479-495. 
Rose, J., Pedersen, K., Hosbond, J.H., \& Kræmmergaard, P. (2007). Management competences, not tools and techniques: A grounded examination of software project management at WM-data. Information and Software Technology, 49 (6), 605-624.

Sakthivel, S. (1994). A decision model to choose between software maintenance and software redevelopment. Journal of Software Maintenance: Research and Practice, 6 (3), 121-143.

Schmidt, R.C. (1997). Managing Delphi surveys using nonparametric statistical techniques. Decision Sciences, 28 (3), 763-774.

Schmidt, R.C., Lyytinen, K., Keil, M., \& Cule, P. (2001). Identifying software project risks: an international Delphi study. Journal of Management Information Systems 17 (4), 5-36.

Shim, J.T., Sheu, T.S., Chen, H.G., Jiang, J.J., \& Klein, G. (2010). Coproduction in successful software development projects. Information and Software Technology, 52(10), 1062-1068.

Siegel, S. (1956). Nonparametric Statistics for the Behavioral Sciences. New York: McGrawHill.

Soto-Acosta, P., Casado-Lumbreras, C. \& Cabezas-Isla, F. (2010). Shaping human capital in software development teams. The case of mentoring enabled by semantics. IET Software, 4(6), 445-452.

Strauss, A., \& Corbin, J. (1990), Basics of Qualitative Research: Grounded Theory Procedures and Techniques. London: Sage.

Thanasankit, T. (2002). Requirements engineering - exploring the influence of power and Thai values. European Journal of Information Systems, 11 (2), 128-141.

Tichon, J.G., \& Wallis, G.M. (2010). Stress training and simulator complexity: why sometimes more is less. Behaviour \& Information Technology, 29 (5), 459-466.

Wang, J., \& Lin, Y.I. (2003). A fuzzy multicriteria group decision making approach to select configuration items for software development. Fuzzy Sets and Systems, 134 (3), 343-363. 